\title{
Support provision for students with Special Educational Needs in Irish Primary Schools
}

\section{Richard Rose and Michael Shevlin}

\section{Introduction}

The means through which effective support can and should be provided for students with special educational needs attending mainstream schools, is an issue that has been subject to debate for some considerable time (Hunt, Soto, Maier and Doering 2003; Wedell 2005). As the promotion of greater inclusion of students into mainstream classrooms has gathered momentum (Winzer and Kas 2012; Florian 2014) the necessity to examine the efficacy of practices to ensure that their learning is appropriately managed has become increasingly apparent (Erten and Savage 2012; Thomas 2013). This paper discusses the findings from a four-year longitudinal research project into provision for students with special educational needs within the Republic of Ireland (Project IRIS), and specifically discusses the variety of approaches to the provision of support that these students receive in mainstream schools. We begin by outlining the rationale for this study, followed by an examination of the international literature on support provision. The specific Irish policy and legislative context for support provision will be outlined.

On the basis of the data collected through field work conducted across Ireland, the authors suggest that there are several models of support 
provision in evidence in schools, but that the efficacy of these has been subjected to little critical evaluation, and that some may be inhibiting rather than fostering the development of educational provision that is genuinely inclusive. The perceptions of service users (students and parents/carers) and service providers (teachers, school principals and classroom support staff) are useful in providing insights into both the rationale for the provision of modes of support delivery, and the impact of these upon student experiences. These perceptions were interrogated through the research and the data provided through interviews and focus groups were verified through in-situ observations in classrooms and on playgrounds and via a scrutiny of school documentation. This latter approach included an analysis of school policies and planning procedures alongside records of student achievement and attainment. A broader overview of the provision made in schools was obtained through a national survey conducted with a stratified sample of schools in order to place the qualitative data within a wider national context.

\section{International perspectives on support provision}

Over the last twenty years inclusive education has become the dominant paradigm informing international policies and landmark agreements across the world (Armstrong, Armstrong, and Spandagou, 2011). The impetus for establishing inclusive education originated in a wider societal drive to address the disadvantage and discrimination experienced by marginalised individuals and communities. Many countries have 
developed policies and legislation that reflect international thinking about the value of inclusive education (Ainscow, Booth and Dyson 2006). Despite the overwhelming support for inclusive education a common definition of what constitutes inclusive education in practice has proved elusive (Slee, 2011). Two key conceptualisations have emerged: a narrow interpretation of inclusion which focuses on integrating pupils who have disabilities and or special educational needs into mainstream classes and providing the individualised support required; a broader interpretation that emphasises how schools need to become inclusive learning environments that welcomes all children (Loreman, 2014). Despite extensive research that has clearly demonstrated how schools can become more inclusive, achieving the goal of inclusive education has proved immensely challenging (Forlin, Chambers, Loreman, Deppeler and Sharma, 2013). Researchers and practitioners have produced a variety of explanatory models to account for the immense variability in inclusive education practice both within and across countries (Mulholland and $\mathrm{O}^{\prime}$ Connor, 2016): the durability of existing special education processes and practices (Tomlinson, 2012); the emphasis within government policies on placement rather than quality of education (Farrell, 2012); teacher perceptions that they are ill-equipped to teach pupils with diverse needs in mainstream classrooms (Lyons, Thompson and Timmons, 2016); inherent contradictions in establishing a continuum of provision to meet the continuum of need (Rix, Sheehy, Fletcher-Campbell, Crisp and 
Harper, 2013); focus on individualised pupil supports rather than wholeschool approaches to inclusion (Nes, 2014).

Over the last two decades there has been an extensive debate around how and where support for pupils with special educational needs should be provided and delivered (Florian and Spratt, 2013). Forlin (2001) pointed out that there is a considerable variation in how the support teacher role is conceptualised internationally, nationally and at a local level. There is general agreement that the traditional model of withdrawing pupils for support has significant limitations (Anderson and Boyle, 2015, McLeskey, Waldron, Spooner and Algozzine, 2014). Withdrawal for support can lead to pupils being stigmatised (Slee, 2011) and classroom/subject teachers have limited opportunities to develop expertise in teaching pupils who have diverse needs within the mainstream classroom (Horne and Timmons, 2009). Support teachers have been encouraged to develop a more expansive role that involves supporting the classroom teacher in addressing diversity within mainstream classrooms (Crowther, Dyson and Millward, 2001). SENCOs (Special Education Needs Coordinators) were appointed in many jurisdictions with the expectation that they would take a proactive role in leading change in how support was conceptualised and delivered at the level of the whole school (Emanuelsson, 2001). However, implementing this type of radical change has proved to be problematic and challenging (Whalley, 2018). Categorical thinking often informed school responses 
where difficulties in learning were attributed to within pupil deficits (Emanuelsson, 2001). Pupils with difficulties in learning were perceived to be within the support teacher remit rather than a whole school responsibility (Mc Ghie-Richmond, Irvine, Loreman, Cizman and Lupart, 2013). These types of difficulties were anticipated by researchers almost twenty years ago (Crowther et al., 2001, Forlin, 2001) and have been compounded by the increased emphasis internationally on raising standards (Armstrong et al., 2011, UNESCO, 2012).

However, despite the difficulties in implementing inclusive support provision, there have been many examples internationally of proactive government policies and legislation designed to support inclusive learning environments in Australia (Florian et al., 2013), Canada (Horne and Timmons, 2009, Sokal and Katz, 2015), Scandinavian countries (Nes, 2014, Wendelborg and Tøssebro, 2011), Europe (European Agency for Development in Special Needs Education (EADSNE), 2010, Mortier, Van Hove \& De Schauwer, 2010), United States (McLeskey et al., 2014, Waitoller and King Thorius, 2015) and the United Kingdom (Ainscow, 2005, Riddell, Tisdall, Kane, and Mulderrig. 2006). International exemplars of effective school reform encompassing an inclusive education perspective have emerged including Canada (Lupart and Webber, 2012) and Australia (Florian et al., 2013) which focused on whole school approaches and in-class support such as differentiated curriculum, alternative curricula, Universal Design for Learning and quality teaching 
for all. Examples of highly developed collaboration between support and classroom teachers and co-teaching have been reported in Scandanavia (Nes, 2014), Australia (Armstrong and Boyle, 2015, Deppeler, 2012) and Canada (Lyons et al., 2016). However, while positive exemplars of inclusive support provision have been reported internationally this is far from universal. Richardson and Powell (2011) observed that international inclusion practices were typified by the common language employed rather than demonstrating radical changes in policies, practices and attitudes. Rix et al. (2013) conclude that while there are increasing numbers of pupils identified as having special educational needs there has been little change in the numbers in segregated provision. In a recent study of provision in Italy and Norway, Nes, Demo and Ianes (2018) reported an increase in the removal of pupils with special educational needs from mainstream classrooms despite explicit policies in both countries advocating within class support. In Norway, the authors report that the majority of pupils receive special education lessons in small groups outside the classroom (66\%); one on one support (14\%) and approximately $20 \%$ of pupils receive support exclusively within the classroom. This study challenges the inclusive principles underpinning Italian and Norwegian school systems, though the authors suggest that learning outside the classroom that involves regular education differentiation could be viewed positively as a way to use small group learning flexibly and create a supportive environment. Paraprofessionals such as Teaching Assistants (TAs) have become significant participants in 
support provision in many countries (Giangreco and Doyle, 2009). While their contribution can be very valuable serious concerns have been raised in situations where Teaching assistants become, in effect, the main teachers for pupils who are deemed too difficult to include in mainstream classrooms (Giangreco and Doyle, 2009, Webster et al., 2010). Pupils, when consulted, prefer a lighter form of paraprofessional support which is unobtrusive and scaffolds their education (Whitburn, 2013).

It is evident that establishing inclusive learning environments has and continues to face many challenges. Developing support provision that does not further marginalise pupils has proved problematic. The traditional individualised models of support are very much in evidence despite concerted efforts to create effective models of in-class support based on increased teacher collaboration and whole school approaches.

\section{The policy and legislative context}

Over the last two decades there has been a rapid development in the Republic of Ireland of policy and enabling legislation designed to support children and young people with special educational needs within the education system. The 1998 Education Act (Oireachtas 1998), which provides the statutory basis for the education of all children of compulsory school age explicitly refers to the provision of appropriate educational supports for children with special educational needs. The Equal Status Act (Oireachtas 2000) supports the thrust of the Education Act by requiring 
schools to provide reasonable accommodation to ensure that children with special educational needs can benefit from educational provision. However, the Education for Persons with Special Educational Needs (EPSEN) Act (Oireachtas 2004) represents a milestone in the development of enabling legislation that has established the National Council for Special Education (NCSE) designed to provide an infrastructure at national and local level to support the education of children with special educational needs. A continuum of educational provision is available ranging from full-time placement in a mainstream class to full-time placement in a special school and a number of options are available between these two types of provision, including enrolment in a special class in a mainstream school. The Department of Education and Skills (DES) and the National Council for Special Education (NCSE) share responsibility for the allocation of resources to support children with special educational needs. Resources are allocated according to a categorical model (14 categories of disability/special educational needs) which are divided into 'high incidence' disabilities those more frequently occurring (including mild intellectual disability, dyslexia) and 'low incidence' disabilities those that occur less frequently (including autism, physical/sensory disabilities). The General Allocation Model (GAM) administered by the DES at primary level supports those children deemed to be in a 'high incidence' category of special educational need and generally consisted of extra teaching staff depending on the size and the socio-economic status of the school. Students in the 'low incidence' 
categories must receive a professional assessment and are allocated individual support hours delivered by a resource teacher and may be assigned a Special Needs Assistant and technology support as deemed appropriate. A review of the General Allocation Model (Department of education and Skills 2012) concluded that this had achieved key aims including the provision of permanent staffing in schools guaranteeing access to support, and the establishment of support teaching teams who can collaborate on developing more flexible teaching approaches.

Methodology

In order to ensure data that was trustworthy a mixed methods approach was adopted by the researchers. Burke Johnson and Onwuegbuzie (2004) challenge what they see as a limiting approach to the establishment of a research approach which continues to foster the differences between positivist and interpretivist paradigms. They suggest that both quantitative and qualitative researchers attempt to answer complex questions based upon their observations of phenomena which can inform their understanding. For this reason they propose that an approach which adopts both qualitative and quantitative data collection methods is wholly appropriate to research in the social sciences.

For researchers conducting longitudinal studies the use of mixed methods has particular value. Plano-Clarke et.al. (2015) have identified a growing trend in the use of mixed methods design in longitudinal studies. In particular they note the potential for the quantitative and qualitative 
strands to interact within and across the multiple points of data collection (page 314). In this way the findings from one method may be used to inform both the development and implementation of other methods and can enhance the process of interpretation. This was certainly the case in the research described in this paper. The survey adopted by the research team provided a broad perspective of the situation in providing special and inclusive education across Ireland. The findings from this survey were used to inform the development of the qualitative (interview, focus group and observation) methods deployed to acquire the necessary depth to provide detailed school and individual case studies. The findings from the phase 1 data collection process enabled the research team to modify those instruments designed for use at phase 2 .

In reporting the findings of the research, the team were able to thus provide both a broad analysis of provision across Ireland and a more nuanced and in-depth picture of how policy, provision, experiences and outcomes impacted the lives of children and their families. We would argue that a more limited approach using exclusively qualitative or quantitative approaches would have restricted the ability of the researchers to provide the overview of provision required by the project funders and would similarly have restricted the potential for influencing further developments in special and inclusive education across Ireland.

\section{Methods}


Data were collected from a national electronic survey of a representative sample of schools, and field visits to primary schools across the country. The quantitative data from the survey was subjected to statistical analysis, to provide a picture of service provision across Ireland. The survey consisted of 46 items distributed across five sections designed to elicit data related to four key themes of policy, provision, experience and outcomes in addition to providing demographic information. Each section comprised a mix of question types, including those based upon a five point Likert rating scale, multiple-choice and open ended questions. The qualitative data from the survey was further interrogated through thematic analysis to provide insights into school responses to current policy initiatives and the methods of support provided for students in schools.

Quantitative data collected through the survey were managed through the use of statistical software (Statistical Package for the Social Sciences 2012) which allowed for the weighting of each respondent in order to ensure that adjustment could be made for disproportionate samples and representativeness assured. This was achieved by multiplying each respondent by a weighting factor, which was determined by the proportion of the respective variable in the population, divided by the proportion of that variable in the respondents.

The quantitative data from the survey was processed on several levels, using statistical analysis to reflect the complexity of variables within the 
dataset. The data obtained through Likert scales were compacted (Linacre 2002) thereby increasing the test reliability for the sample (Zhu et.al. 1997), and reflecting the functioning of the scale for that sample (Rasch 1960). This combining of categories also served to improve the overall quality of the measure (Wright and Linacre 1992).

\section{INSERT TABLE 1 HERE}

Illustrative case studies were developed in order to provide a picture of the influences of policy and provision on the experiences and outcomes for students with a diverse range of needs and abilities (Rose and Shevlin 2014). These case studies were formulated on the basis of interviews conducted with key personnel in a sample of 10 primary schools and a scrutiny of school documentation. The schools were selected for the compilation of case studies on the basis of key variables identified as a means of ensuring that the sample was broadly representative of primary schools in Ireland. Table 2 below provides a breakdown of the schools within the case study sample and discussed within this paper.

The vast majority of primary schools in Ireland are under denominational control. Within the sample for this research, seven of the schools (National Schools) are under the patronage of the Roman Catholic Church, one school is under the patronage of the Church of Ireland, the one Educate Together school in the sample is multi-denominational and the remaining sample school is a Gael Scoil where the medium of instruction is through the Irish language. 


\section{INSERT TABLE 2 HERE}

Each school was visited twice with an interval of two years between the visits, and two researchers spent a minimum of two days in the school on each visit. Interviews were conducted in the schools with key service providers and users (see table 3 below). These were semi-structured in nature and consisted of both parallel questions aimed at obtaining differing perspectives on similar issues from a range of viewpoints, and interviewee specific questions which intended to gain data in respect of personal roles and experiences. For example, all respondents were asked questions related to the types of support provision made, enabling a broad picture of modes of support across an individual school to be obtained, whilst each individual respondent was also asked to provide their unique experiences of the efficacy of this provision.

Interviews were face to face, and conducted by a member of the research team. Children were always interviewed in the presence of a known adult and in some instances augmentative communication support in the form of known symbols or the use of technological aids was used to enable participation.

All interviews were transcribed and independently blind coded by two members of the research team. The use of thematic codes was consistently applied across all data obtained through interviews, document scrutiny and the qualitative responses to the national survey, and enabled these to be managed effectively. Coding by two individuals 
allowed for trustworthiness of interpretation to be achieved (Patton 2002). Where there were differences of interpretation, these were discussed, and if the data remained unclear it was not used, in order to retain a high level of trustworthiness. Data obtained in interviews were further verified through a scrutiny of school documentation, including lesson plans, student records and school timetables using the same thematic codes. This multi-methods approach to triangulation enabled the researchers to establish a picture of the types of support provided for students, along with the frequency with which the approach was used, and the personnel involved.

\section{INSERT TABLE 3 HERE}

\section{Findings}

The findings presented here relate to the key elements of support provision as identified through the national survey and validated through the data collected in case study schools Five elements were identified (as outlined below), but it is evident that these fall into two specific groups. The first of these concerns the organisation of support outside of the classroom environment, and the second is more focused upon in-class support.

The national survey responses indicated that support for students with special educational needs in primary schools was seen to be managed both within and outside of the classroom Table 4 (below). These data, 
obtained from the national survey and verified from interviews indicate that in addition to curricular modifications and differentiated approaches to teaching made by classroom teachers, five approaches to the provision of support were seen to be used.

\section{INSERT TABLE 4 HERE}

The use of support staff in addition to the class teacher is a critical factor in each of the five approaches presented in table 4. In Ireland, the deployment of resource teachers and learning support teachers as specialists in schools is a common practice. Professionals with these designated roles have responsibility for maintaining an overview of special educational needs provision in schools. They additionally provide guidance and support to class teachers, often take a lead role in assessment and recording procedures, and maintain links with parents. There are parallels here with delegated responsibilities within schools for special educational needs management in other countries, such as the special education teacher USA (McLesky, Tyler and Flippin 2004), the special educational needs co-ordinator (SENCo) in the UK (Qureshi 2014), the special education teacher in Cyprus (Liasidou and Antoniou 2013) and the special teacher in Finland (Takala., Sarromaa Haussttätter., Ahl, and Head, 2012). In each of these administrations the specialist teacher can be seen as providing a focus for management of provision for students with special educational needs within the school. However, the ways in which these professionals fulfil their roles and responsibilities vary considerably 
and may even differ within a single administration (Gersten, Keating, Yovanoff, and Harniss, 2001; Lindqvist and Nilholm 2013). Similarly the availability and distribution of specialist teachers is not always consistent and may well vary across areas according to variables related to poverty, rural deprivation or culture (Katsiyannis, Zhang and Conroy 2003; MasonWilliams 2015) and therefore caution needs to be exercised when discussing the operational aspects of support.

\section{Support provided outside of the classroom}

In Ireland, in addition to an essential administrative role, one which involves an oversight of planning and provision, resource teachers and learning support teachers have a significant responsibility for teaching individuals and groups of children with special educational needs. In some instances this role is performed within the classroom, but data shows that teaching in withdrawal situations is a regular feature of the support provided as indicated in the national survey and evidenced in all ten primary schools in the research case study school sample.

Class teachers and support teachers often favour this approach, and believe that when students are taught in an environment away from the classroom they may have opportunities to participate in learning in ways that are less often possible in whole class situations, as this support teacher observed.

"So I have been working with two girls I've been working with individually, I was working with them in a group last year, and they would 
not have made near as much progress as they've made this year, because the programmes' tailored to meet their needs and not the person sitting beside them like, so I know in some cases that's important, but I definitely think you need the one on one as well."

(Support Teacher).

This sentiment was endorsed by a class teacher who also perceived advantages in taking students out of class.

"She [A nine year old student with hearing impairment] goes off to her class where she can excel and come out, and it's good that they get a chance to be withdrawn where they can talk in a smaller group, because their little voices would not be, particularly [names a child with learning difficulties and another with hearing impairment] would not be heard as much".

\section{(Class Teacher)}

Whilst the opinions of this teacher regarding the benefits of small withdrawal group support was typical of others reported during interviews, it was apparent that few had experienced an opportunity to attend withdrawal sessions, and were generally reporting their efficacy mainly on the basis of discussions with their specialist teacher colleagues. The work undertaken with students by specialist teachers in small group situations was most often designed to remediate specific difficulties such as those associated with reading or numeracy, and was seldom directly 
related to the curricular focus applied in the mainstream classroom. However, where this did occur, some students were able to articulate the benefits that they thought were to be gained from working in small withdrawal group situations.

An example of this was provided by a student who, whilst being aware that there was a possible stigma attached to attending a separate group, could also identify how she had been helped by this process.

"I go out for English and someone said to me that 'oh you go out for extra help, you always get everything wrong', and then one day someone said that to me and I came back to the classroom like, we were filling in the blanks the same as the girls, and the girl that said that to me got three wrong, and I got all of them right".

(10 year old Student with dyslexia)

Resource and learning support teachers sometimes indicate that the benefits which they perceive to be gained by students in withdrawal situations are likely to be social or behavioural as much as academic. "A lot of the work we're doing is around sort of behavioural work, how to identify things, feelings, and how to resolve conflicts ...I wouldn't be specifically working on his actual academic work

(Resource teacher) 
In some schools it was possible to observe a changing pattern in relation to this form of support with school principals and some teachers questioning the overall impact of withdrawal. One school principal suggested that whilst the use of small group withdrawn activity had once been common practice and could still be observed in his school, he was now advocating a greater focus on in-class support.

"I think it's good practice because the children aren't withdrawn from their classes as much as they were. I have a problem with, particularly children on the ASD spectrum, missing five hours of school a week, the fact that they had an SNA and they were getting five hours of resource teaching meant that they weren't able to work independently, so to a certain degree it could be counterproductive, withdrawing children from class too often."

(School Principal)

A teacher in another primary school reinforced this view by reporting changing patterns of support in the school where she was working.

"Most of our support lately is in class, which we feel has more, - it's less kind of intrusive, and the kids are less aware that they're actually getting support".

(Class Teacher)

However, opinions of this nature were expressed by relatively few teachers, and the use of withdrawal continues to be a dominant model of 
providing support for most students with special educational needs in Irish primary schools and was still a preferred option in all ten case study primary schools.

\section{Teaching in separate groups for part or the whole of a school day}

There were very few examples of students in mainstream primary schools being taught in separately designated classes for either part or whole days. However, in two of the case study schools specialist reading classes had been established and were managed by teachers with additional qualifications in the teaching of reading. The students who attended these classes generally had a diagnosis of dyslexia, and were seen by the staff in these schools as requiring specialist additional support that would enable them to access the curriculum as a whole.

The focus upon the acquisition of literacy skills is prevalent in schools with reading units. There is a perception that the removal of students from mainstream classes to receive intensive remediation in these areas may enable them to eventually succeed in working alongside their peers, Teachers working in these units cite the small class group size as being a critical factor. They also generally perceive that support of this nature should be time limited and focused upon returning students to the mainstream class.

"So when they come to us we try to have a very open very supportive, very encouraging classroom. Somewhere where they feel safe, somewhere that they can understand there's other kids going through the 
same thing as they are, that they're not the only one who's having difficulties or having problems".

(Teacher in a reading unit)

Whilst there were suggestions that student performance in reading improved during their time working in the specialist reading units, there was little evidence that the transferability of the skills learned enabled them to function more effectively on their return to the mainstream. Similarly, there was little discussion within these schools related to whether this intense approach to remediation was enabling students to access the broader aspects of the curriculum afforded to their mainstream class peers.

Although concerns were expressed by some teachers that the use of special classes could isolate students from their peers and possibly restrict their curriculum diet, the students attending these units were often positive about the support that they received.

"It gives you more help than other classes when you came in here. Everybody's nice here. They helped you more with your dyslexia, like they have special things to help, they don't like, they help you more than any other teachers because you're in the special class".

(10 year old student attending a reading unit) 
Parents were also supportive of the use of these separate classes and often felt that they provided the level of intervention that was not possible in the mainstream class.

"Well I think the teachers down in the reading class are amazing ... they take immense time, not just to be a teacher, they're like a mentor ... the fact that the class is small helps, because she's not in a class of twenty five or thirty people, she gets that little bit more attention".

(Parent of 11year old student with specific learning difficulties)

Teachers working in the schools where there were separate units, saw no contradiction between a policy that advocated inclusion (seen in all ten schools) and this type of provision. The fact that these units are located in mainstream schools appeared to justify the existence of this form of provision, even when students were enabled to spend a relatively small proportion of their time with their mainstream class peers.

\section{Support provided in the classroom}

In some schools there were clear misgivings about the use of withdrawal or specialist classes for the support of students with special educational needs. Teachers often recognised the potential for students to miss out on essential learning if they were educated separately from their peers. As a teacher in a class which included a pupil with a hearing impairment and another on the autism spectrum observed. 
"I think it's important that any activities that are done in class, that everybody is able to participate and be included in that activity, at maybe different ability levels, and obviously differentiated towards their abilities".

(Class Teacher)

The teacher making this comment worked in a school where policy promoted the provision of support from resource teachers and paraprofessionals within the classroom, and working directly under the direction of the teacher. This approach is being increasingly seen in Irish primary schools though as yet it cannot be said to be the norm. However, teachers are aware of the need to take a more differentiated approach to planning and the delivery of lessons, and recognise that classes of diverse student needs demand both access to specialist resources and innovative approaches to teaching. As one teacher noted, this requires a different way of thinking about the classroom environment and the ways in which peer support can be encouraged. She commented on how a teacher with whom she worked had analysed the ways in which the most effective classroom support could be provided.

"Co-operation, turn taking, a lot of social stories, sequencing and then behaviour, like managing his space, did you see in the classroom, the tables were halved, that's so [names a 6 year old child with severe learning difficulties] can manage his space. So the classroom teacher incorporated that with the whole class, so she wouldn't just isolate him." 
Observation by the research team in this classroom revealed that communication between the teacher, learning support teacher and a special needs assistant was of a high calibre, with all three professionals closely involved in the planning delivery and evaluation of every lesson.

A different learning support teacher was aware of the need to ensure that resourcing and adaptation of the environment was in place in order to ensure that effective teaching could occur. Whereas previously this support teacher had been responsible for providing teaching outside of the classroom, she now saw her role as being one of ensuring that the correct conditions for learning were provided within the class.

"[Names a 5 year old child with hearing impairment] has moderatesevere sensory neural hearing lost. There is a sound system in her classroom to help her cope with this. She is to be seated in the front of the classroom so that she can lip read what the teacher is saying. She also has hearing aids".

(Learning Support Teacher)

\section{Support within the classroom from a Special Needs Assistant}

In addition to the support provided by resource teachers, some students with special educational needs have a designated special needs assistant who works with them under the direction of the class teacher. This is a common model of support provided in primary schools across Ireland 
(Logan 2006, Rose and O'Neill 2009, Keating and O'Connor 2012); it is also an approach to be found within many other administrations (Giangreco, Carter, Doyle and Suter 2010; Giangreco, Doyle and Suter 2014; Bartz, Kurth, and Wangeman 2015).

Special needs assistants in Irish primary schools see their role as being one of supporting inclusion by ensuring that students can access all aspects of learning.

"So my work basically is mainly to make sure that a special needs child has the full inclusion of the day, that he has access to everything, and that means the whole curriculum and the social and emotional side as well. When he [Student] takes a strop during the day, I have more time to be able to find out exactly what is wrong, where in a normal day a teacher wouldn't have a huge amount of time to find out exactly what his problem is."

(Special Needs Assistant working with a five year old student on the autism spectrum and with general learning difficulties)

Parents in the school samples often perceived special needs assistants as being essential to enabling their child to be maintained within a mainstream learning environment. In particular they believed that the opportunity to build a close and consistent working relationship with someone who knew their child's individual foibles and needs enabled them to access lessons more effectively. As one parent commented: 
"For my son what was essential and has proven to work is having some consistency, so we have somebody dedicated who works with him permanently and we think that will actually expedite improvements in his behaviour and his life generally".

(Parent of a 6 year old student with ADHD) Another parent acknowledged the need to try and decrease the level of support provided for her son, and similarly to some teachers interviewed observed that his need for support was more closely related to social, emotional and behavioural issues than to curriculum access.

"He's very different from when he started school, he's a different child altogether, he got a full time SNA when he started and then he's had an SNA up until this year, they're trying to kind of phase it out, but I don't think he could have got this far without his SNA ... it's kind of, it's not even academically he's fine, he's very clever, it's emotional support for him, you know that kind of thing".

(Parent of a 10 year old child on the autism spectrum)

Teachers often perceived the availability of special needs assistants as being essential if they were to include students with complex needs in their classrooms. They acknowledged that having this kind of support required a greater level of planning in relation to classroom activities, but did not see the role of the special needs assistant as one that could 
potentially create dependency, or cause students to feel that they were different from their peers.

\section{Discussion and conclusions}

The EPSEN Act (Oireachtas 2004) and guidance documents from government organisations in Ireland (National Council for Special Education 2011) have done much to provoke debate about how support should be provided to students who experience difficulties with learning. A commitment to inclusion is clearly stated within this documentation and is in evidence in some of the procedures adopted by Irish schools (Rose, Shevlin, Winter and O'Raw 2010; Lysaght 2012; Casserly and Padden 2018). However the current approaches to promoting a more inclusive education system are in a period of transition, from a model that saw segregation and withdrawal as the norm to one in which greater consideration is given to pedagogical approaches that are more inclusive (Shevlin, Kenny and Loxley 2008; Banks, Frawley and McCoy 2015).

The withdrawal of students with special educational needs from their classroom to receive support from a specialist teacher has been a common model in schools in many administrations (Norwich and Lewis 2001; Croll and Moses 2003; Anderson and Boyle, 2015). However, critics of this approach (McLeskey, Waldron, Spooner and Algozzine, 2014; Butt 2016) suggest that this is counterproductive if schools wish to endorse methods that encourage more inclusive learning (Whitburn 2013; Ainscow 2014). The research reported in this paper suggests that Withdrawal is 
still a dominant approach to educating students with special educational needs in Irish mainstream primary schools.

The authors of this paper suggest that the dependency upon withdrawal and the current approach to using specialist teacher and para-professional support is impeding progress towards inclusion. It does so initially by investing expertise in a limited number of adults upon whom other teaching staff become dependent. Teachers in many Irish classrooms whilst seen to be well organised and effective in their practice, maintain approaches that can lead to the abdication of responsibility to "expert" colleagues. Furthermore, the pressures of working in busy classrooms mean that effective communication between specialist teachers and class teachers, to ensure that there is consistency of approach, and that curriculum coverage is achieved is often limited.

Observations conducted in primary school classrooms during the course of field work revealed that teachers use a limited range of differentiation strategies. This, we suggest, results in part from the use of withdrawal teaching which is seen to lessen to need for differentiated instruction in class and thereby limits the urgency of teachers to develop strategies in this area.

This situation was particularly in evidence in schools that used separate reading classes for those students who exhibit difficulties with literacy or basic numeracy. Whilst there is evidence from the literature that students within these classes make progress (Casserley and Gildea 2014), it was 
apparent that the students attending received a narrower curriculum diet than their mainstream class peers.

Teachers in Irish primary schools demonstrate an awareness of the national policy aimed at creating more equitable learning environments. There is a clear pattern of increased influences from this policy on training initiatives, and in the development of school policies. The commitment of school principals and teachers towards exploring the means by which inclusive schooling can be fostered is not in doubt. We would suggest that a more critical and self-reflective analysis by schools of the procedures that they are adopting, would prove fruitful as teachers endeavour to achieve inclusive education in Ireland.

The authors suggest that the insights provided through this research should be used to inform discussions in schools and by policy makers and providers of professional development in order to review the efficacy of support provision made. In particular, consideration should be given to the use of of withdrawal of students from classrooms where this may have implications for their ability to access a full and balanced curriculum. Where this form of support persists, there must be an increased awareness of the need to ensure effective communication processes between para-professional and teaching staff. Where this level of communication is limited, there is little guarantee of curriculum continuity, or the application of remediation approaches conducted in segregated sessions within whole class teaching. 


\section{References}

Ainscow, M. (2005) "Developing Inclusive Education Systems: What are the Levers for Change?" Journal of Educational Change 6 (2) 109-124.

Ainscow, M., Booth,T, \& Dyson, A. (2006), Improving Schools, Developing Inclusion. London: Routledge.

Ainscow, M. (2014) From special education to effective schools for all: widening the agenda. In L, Florian (Ed.) The Sage Handbook of Special Education. London: Sage

Armstrong, D., A., Armstrong, C, \& Spandagou, I. (2011) "Inclusion: by Choice or by Chance?" International Journal of Inclusive Education 15 (1) 29-39.

Banks, J., Frawley, D, \& McCoy, S. (2015) Achieving inclusion? Effective resourcing of students with special educational needs. International Journal of Inclusive Education, 19 (9) 926-943

Bartz, J, M., Kurth, J, \& Wangeman, M. (2015) Facilitating supports and services for learners with low-incidence disabilities. In E, A, West (Ed.) Including Learners with Low-Incidence Disabilities. Bingley: Emerald Burke Johnson, R, \& Onwuegbuzie, A. J. (2004) Mixed Methods Research: A Research Paradigm Whose Time Has Come. Educational Researcher, 33 (7) 14-26

Butt, R. (2016) Teacher assistant support and deployment in mainstream schools. International Journal of Inclusive Education 20 (9) 995-1007 
Casserly, A, M, \& Gildea, A. (2014) A review of a reading class placement for children with dyslexia, focusing on literacy attainment and pupil perspectives. European Journal of Special Needs Education. 30 (3) 304322

Casserly, A.M, \& Padden, A. (2018) Teachers' views of co-teaching approaches in addressing pupils with special educational needs (SEN) in multi-grade classrooms European Journal of Special Needs Education. 33 (4) $555-571$

Croll, P, \& Moses, D. (2003) Special educational needs across two decades: survey evidence from English primary schools. British Educational Research Journal. 29 (5) 731 - 747.

Crowther, D., Dyson, A. \& Millward, A. (2001) Supporting pupils with special educational needs: issues and dilemmas for special needs coordinators in English primary schools, European Journal of Special Needs Education, 16 (2) 85-97.

Department of Education and Skills (2012) Review of the Primary Schools' General Allocation Model. Dublin: DES

Emanuelsson, I. (2001) Reactive versus proactive support coordinator roles: an international comparison, European Journal of Special Needs Education, 16 (2) 133-142

Erten, O, \& Savage, R.S. (2012) Moving forward in inclusive education research. International Journal of Inclusive Education. 16 (2) 221-233 
European Agency for Development in Special Needs Education (2010). Inclusive Education in Action - Project Framework and Rationale, Odense, Denmark: European Agency for Development in Special Needs EducationFlorian, L. (2014) What counts as evidence of inclusive education?, European Journal of Special Needs Education, 29 (3) 286294.

Florian, L., and Spratt, J. (2013). "Enacting Inclusion: A framework for Interrogating Inclusive Practice." European Journal of Special Needs Education 28 (2) 119-135.

Forlin, C. (2001) The role of the support teacher in Australia, European Journal of Special Needs Education, 16 (2) 121-131.

Forlin, C., Chambers, D., Loreman, T., Deppeler, J. \& Sharma, U. (2013). Inclusive Education for Students with Disability: A Review of the Best Evidence in Relation to Theory and Practice. Canberra, Australia: Australian Research Alliance for Children and Youth (ARACY).

Gersten, R., Keating, T.,Yovanoff, P., \& Harniss, M. K. (2001). Working in special education: A study of factors that enhance special educators' commitment and intent to remain in the field. Exceptional Children. 67 (4) 549-567.

Giangreco, M. F., Carter, E. W., Doyle, M. B, \& Suter, J. C. (2010). Supporting students with disabilities in inclusive classrooms. In R, Rose (Ed.) Confronting Obstacles to Inclusion. London: Routledge. 
Giangreco, M. F., Doyle, M. B, \& Suter, J. C. (2014). Teaching assistants in inclusive classrooms. In L, Florian (Ed.) The Sage Handbook of Special Education. London: Sage Horne, P, \& Timmons, V. (2009). "Making it Work: Teachers' Perspectives on Inclusion." International Journal of Inclusive Education 13 (3) 273286.

Hunt. P., Soto. G., Maier. J, \& Doering. K, (2003), Collaborative teaming to support students at risk and students with severe disabilities in general education classrooms. Exceptional Children. 69 (3) 315-332.

Katsiyannis, A., Zhang, D, \& Conroy, M. A. (2003), Availability of special education teachers: trends and issues. Remedial and Special Education. 24 (4) $246-25$

Keating, S, \& O'Connor, U. (2016) The shifting role of the special needs assistant in Irish classrooms: a time for change? European Journal of Special Needs Education 27 (4) 533 - 544

Liasidou, A, \& Antoniou, A. (2013) A special teacher for a special child? ( $R e$ )considering the role of the special education teacher within the context of an inclusive education reform agenda. European Journal of Special Needs Education. 28, (4) 494 - 506.

Linacre, J. M. (2002) Optimizing rating scale category effectiveness. Journal of Applied Measurement. 3 (1) 85 - 106 
Lindqvist, G, \& Nilholm, C. (2013) Making schools inclusive? Educational leaders' views on how to work with children in need of special support, International Journal of Inclusive Education, 17 (1) 95-110

Logan, A. (2006) The role of the special needs assistant supporting pupils with special educational needs in Irish mainstream primary schools. Support for Learning 21 (2) 92 - 99.

Loreman, T. 2014. "Measuring Inclusive Education Outcomes in Alberta, Canada." International Journal of Inclusive Education 18 (5) 459-483 Lyons, W., Thompson, S.A. \& Timmons, V. (2016) 'We are inclusive. We are a team. Let's just do it': commitment, collective efficacy, and agency in four inclusive schools, International Journal of Inclusive Education, 20 (8) $889-907$.

Lysaght, Z. (2012) Towards inclusive assessment. In T, Day, \& J, Travers. (Eds.) Special and Inclusive Education: A Research Perspective. Oxford: Peter Lang.

Mason-Williams, L. (2015) Unequal Opportunities: A Profile of the Distribution of Special Education Teachers. Exceptional Children. 81 (2) $247-262$

Mc Ghie-Richmond, D., Irvine, A., Loreman, T. \& Cizman Lupart, J. (2013). Teacher Perspectives on Inclusive Education in Rural Alberta, Canada. Canadian Journal of Education, 36, (1), 195-239. 
McLesky, J., Tyler, N.C, \& Flippin, S.S. (2004). The Journal of Special Education 38 (1) 5-2

McLeskey, J., Waldron, N. L., Spooner, F, \& Algozzine, B. (2014). "What are Effective Inclusive Schools and Why are They Important?" In J. McLeskey, N. L. Waldron, F. Spooner, \& B. (Eds.) Algozzine,Handbook of Effective Schools: Research and Practice. New York: Routledge.

Mortier, K., Van Hove, G. \& De Schauwer, E. (2010) Supports for children with disabilities in regular education classrooms: an account of different perspectives in Flanders, International Journal of Inclusive Education, 14 (6) $543-561$,

National Council for Special Education (2011) Inclusive Education Framework: A guide for schools on the inclusion of pupils with special educational needs. NCSE: Trim

Nes, K. (2014). "Inclusive Education in Norway: Historical Roots and Present Challenges." Journal of Special Education Research 2 (2) 81-86.

Nes, K., Demo, H. \& Ianes, D. (2018) Inclusion at risk? Push- and pull-out phenomena in inclusive school systems: the Italian and Norwegian experiences, International Journal of Inclusive Education, 22 (2) 111-129.

Norwich, B, \& Lewis, A. (2001) Mapping a Pedagogy for Special Educational Needs . British Educational Research Journal 27 (3) 313 329.

Oireachtas (1998). Education Act. Dublin: The Stationary Office. 
Oireachtas (2000).Equal Status Act. Dublin: The Stationary Office.

Oireachtas (2004). Education for Persons with Special Educational Needs Act (EPSEN). Dublin: The Stationary Office.

Organisation for Economic Co-operation and Development (OECD) 2012. "Special Educational Needs (SEN)." Available at http://www.oecd.org/social/ family/50325299.pdf. Accessed 25 April 2019.

Patton, M.Q. (2002) Qualitative Evaluation and Research Methods (3 ${ }^{\text {rd }}$ edition) Thousand Oaks CA: Sage

Plano-Clark, V., Anderson, N., Wertz, J., Zhou, Y., Schumacher, K, \& Miaskowski, C. (2015) Conceptualizing Longitudinal Mixed Methods Designs: A Methodological Review of Health Sciences Research. Journal of Mixed Methods Research. 9 (4) 297-319

Qureshi, S. (2014) Herding cats or getting heard: the SENCo - teacher dynamic and its impact on teachers' classroom practice. Support for Learning 29 (3) $217-229$

Rasch, G. (1960) Probabilistic Models for Some Intelligence and Attainment Tests. Copenhagen: Institute for Educational Research.

Richardson, J., \& J. Powell. (2011) Comparing Special Education. Origins to Contemporary Paradoxes. Stanford, CA: Stanford University Press. 
Riddell, S., K. Tisdall, J. Kane, \& J. Mulderrig. (2006). Literature Review of Pupils with Additional Support Needs: Final Report to the Scottish Executive Education Department. Centre for Research in Education Inclusion and Diversity (CREID).

Rix, J., Sheehy, K., Fletcher-Campbell, F., Crisp, M, \& Harper, A. (2013). "Exploring Provision for Children Identified with Special Educational Needs: an International Review of Policy and Practice." European Journal of Special Needs Education 28 (4) 375-391

Rose, R, \& O'Neill, A. (2009) Classroom support for inclusion in England and Ireland. An evaluation of contrasting models. Research in Comparative and International Education. 4 (3) $250-261$

Rose, R., Shevlin, M., Winter, E, \& O' Raw, P. (2010) Special and inclusive education in the Republic of Ireland: reviewing the literature from 2000 to 2009. European Journal of Special Needs Education. 25 (4) 359 - 373

Rose, R, \& Shevlin, M. (2014) The development of case studies as a method within a longitudinal study of special educational needs provision in the Republic of Ireland. Journal of Research in Special Educational Needs. 16 (2) 113-121

Shevlin, M., Kenny, M, \& Loxley, A. (2008) A time of transition: exploring special educational provision in the Republic of Ireland. Journal of Research in Special Educational Needs. 8, (3), 141 - 152 
Slee, R. (2011). The irregular school: Exclusion, schooling, and inclusive education. Abingdon: RoutledgeTakala, M., Sarromaa Haussttätter, R., Ahl, A, \& Head, G. (2012) Inclusion seen by student teachers in special education: differences among Finnish, Norwegian and Swedish students, European Journal of Teacher Education, 35 (3) 305-325.

Thomas, G. (2013) A review of thinking and research about inclusive education policy, with suggestions for a new kind of inclusive thinking. British Educational Research Journal 39 (3) 473 - 490.

Tomlinson, S. (2012). "The Irresistible Rise of the SEN Industry." Oxford Review of Education 38 (3) 267-286.

Wedell, K. (2005) Dilemmas in the quest for inclusion. British Journal of Special Education 32 (1) 3 - 11.

Wendelborg, C, \& Tøssebro, J (2011). "Educational Arrangements and Social Participation with Peers Amongst Children with Disabilities in Regular Schools." International Journal of Inclusive Education 15 (5) 497512.

Whitburn, B. (2013). The Dissection of Paraprofessional Support in Inclusive Education: 'You're in Mainstream With a Chaperone'. Australasian Journal of Special Education, 37 (2) 147-161. Winzer, M, \& Kas, M. (2012) Analyzing Inclusive Schooling for Students with Disabilities in International Contexts: Outline of a Model. Journal of International Special Needs Education 15 (1) 12-23 
Wright, B.D, \& Linacre, J.M. (1992) Combining and splitting categories.

Rash Measurement Transactions. 6 (3) 233 - 235

Zhu, W., Updyke, W.F, \& Lewandowski, C. (1997) Post-hoc Rasch analysis of optimal categorization of an ordered response scale. Journal of Outcome Measurement. 1 (4) 286 - 304. 